\title{
Physiology of Seasonal Breeding: A Review
}

Vasantha I*

Department of Physiology, NTR College of Veterinary Sciences, Gannavaram-521 102, Vijayawada, Andhra Pradesh, India

*Corresponding author: Vasantha I, Department of Physiology, NTR College of Veterinary Sciences, Gannavaram-521 102, Vijayawada, Andhra Pradesh, India, Tel: +918897094734; E-mail: vasuinjarapu@gmail.com

Rec date: Feb 13, 2016; Acc date: Apr 21, 2016; Pub date: Apr 23, 2016

Copyright: @ 2016 Vasantha I, et al. This is an open-access article distributed under the terms of the Creative Commons Attribution License, which permits unrestricted use, distribution, and reproduction in any medium, provided the original author and source are credited.

\begin{abstract}
The different mammalian species show a wide diversity in methods of breeding. Some of them limit their reproductive activity to certain period of the year while some breed throughout the year. This is to avoid the unfavorable environmental conditions including the non-availability of feed, water, housing etc. However, the difference in breeding strategies lies in the central regulatory system the supra chiasmatic nucleus. It controls the circadian rhythm and the nocturnal drive of melatonin. There by the $\mathrm{GnRH} / \mathrm{LH}$ are under the negative feedback influence of the oestrogen. Change in daylight period is the primary factors those onsets the breeding season. In addition to it, change in oestrogen concentration, neuropeptides, Kisspeptin, GnIH, Thyroid glands and many other environmental factors like availability of food, water, housing, space and climate also influence the onset of breeding.
\end{abstract}

Keywords: Mammalian species; Diversity; Breeding

\section{Introduction}

Animals inhabiting regions in the temperature zone limit their reproductive activity to specific period of time in a year to maximize the survival of their offsprings [1]. Domestic animals are broadly classified as seasonal and non-seasonal breeders depending upon the number of times they breed during a year. Seasonal breeders are those that have specified period of time in a year during which they actively breed. They use the changes occurring in day length as calendar and accordingly regulate many of the physiological and behavioral processes. These are again sub classified based on the number of estrus cycles. Polyestrous are those which have several cycles during each breeding season. Examples of the same include horse, Donkey and sheep, goat. The mentioned species of animals can also be further categorized as long day and short day breeders. The other category of seasonal breeders includes Monoestrus animals which have only one estrus cycle during the breeding season. Non seasonal breeds are those which undergo breeding all through the year irrespective of the season or part of the year. These are polyestrous which says that they cycle all year round at regular intervals. Species which come under non seasonal polyestrous include cattle and pigs. Another form of seasonal breeding is opportunistic breeding. In this the animals are capable of breeding anytime of the year but then exhibit preference to specific conditions. A variation in breeding season in different species is to maximize the survival of their offspring by overcoming the different climatic conditions and also taking into consideration the availability of feed and fodder. Duration of photo period plays a critical role in the onset of breeding season for seasonal breeders. The pineal gland which is said to the neuro endocrine regulator translates the visual signal into hormonal signal thereby showing fluctuation in secretion of melatonin which alters the pulsatile secretion of $\mathrm{GnRH} / \mathrm{LH}$. Thereby controlling the reproductive function. However there are also other neuro peptides which control the reproductive function.

\section{"The physiological basis of the seasonality of breeding in mammals"}

Circadian rhythms and the seasonal variations in the length of the day light are the principal components affecting the reproductive activities in both males and females. The orbiting of the tilted earth around the sun causes circadian changes in the length of the daylight or duration of photoperiod at different seasons of the year. There are many other factors that also change length of photoperiod like fluctuations in environmental temperature, climate variation, availability and quality of feed. The changing photoperiod acts as a bioregulator of reproductive activity and fertility through the mediation of central nervous system, hypothalamus, adenohypophysis and the pineal gland. Onset of breeding season in seasonal breeds is much similar to the onset of puberty [2]. Transition from nonbreeding (anestrous) to breeding (estrous) represents sexually quiescent state to active state [3]. Non breeding season is characterized by an increase in negative feedback effect of estrogen on GnRH and gonadotrophin secretion as is the case in pre-pubertal period [4]. This results in reduced frequency of GnRH pulses, suppressing the gonadotrophin drive to the gonads thereby causing the gonadal regression [3,5]. Until puberty the hypothalamo gonadal axis is under the negative feedback effect of the estrogen. The pulse frequency of $\mathrm{GnRH} / \mathrm{LH}$ is insufficient to stimulate the development of follicles [4]. Sustained increase in estrogen activates the surge center of the hypothalamus thereby creating a positive feedback effect on the hypopthalamus causing surge release of $\mathrm{GnRH} / \mathrm{LH}$. Pre puberty, the small content of estrogen from the developing follicle exerts a negative feedback effect on the hypothamaus, while at puberty the consistently high estrogen exerts a positive feedback effect there by activating the surge center of the hypothalamus and causing for the surge release of LH which causes for the maturtation of the follicle [6]. Pre pubertal period is comparable to non-breeding or anestrous period while the puberty is comparable to the onset of breeding season. Similar kind of transition occurs in both the cases [7]. Therefore the primary mechanism in seasonal breeding is the neural control of pattern of $\mathrm{GnRH}$ from hypothalamus. Pulsatile secretion of $\mathrm{GnRH}$ inturn 
Page 2 of 4

increases the $\mathrm{LH}$ and FSH from the pituitary thereby activating the gonads [8]. The seasonal change in sensitivity to oestrogen is the major mechanism for shift from breeding to non-breeding season (Figure 1) [3].

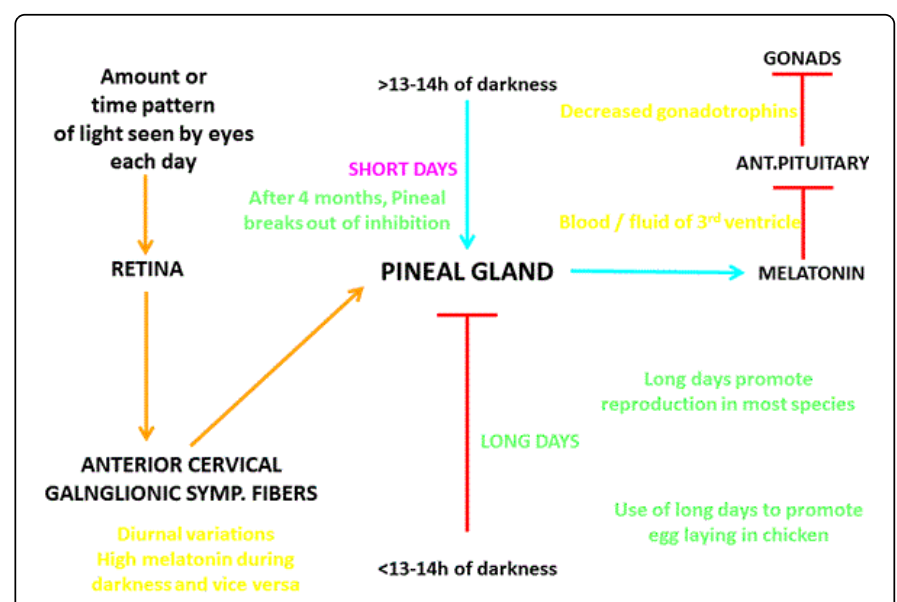

Figure 1: Control of melatonin secretion by day light.

\section{Neural control}

The central circadian regulatory system is located in the suprachiasmatic nucleus. The output of this master clock is synchronized to 24 hours period due to the existing light dark cycle [9]. The SCN regulates the rhythms through the autonomic nervous system in the peripheral cells. The central dogma is that the pineal gland is controlled via a polysynaptic pathway from the SCN. The changes in light-dark cycles are sensitized by the photo pigments of the mammalian eye thereby sending information to the SCN. Darkness stimulates increased melatonin secretion [4]. In this way cyclic production of melatonin is regulated by the SCN [9]. The pineal gland plays a major role as a functional neuroendocrine transducer of the environmental or seasonal change in day light or photoperiod through the activity of N-acetyl transferease (NAT). The role of NAT is that it is the major regulatory enzyme involved in the secretion of melatonin. It converts serotonin to $\mathrm{N}$-acetyl Seratonin. Change in photoperiod from longer days to reduced day light/short days is sensitized by the photo receptors of the eye, which trasmits information to the pineal gland. The pineal gland then translates the information of the photo recetors into neural signal. As a result of which the nor epinephrine from the sympathetic nerve fibers binds to the receptors on the pinealocytes and then through a series of steps causes formation of NAT. melatonin is then released in to the circulation.

\section{Role of melatonin in regulating reproductive activity}

Seasonal variations in photoperiod are perceived by the photo receptors of the mammalian eye sending signals to the SCN. The SCN then drives the nocturnal melatonin rhythm [1]. Long days have more daylight which in turn has less hours of darkness. There by the secretion of melatonin is reduced in season with less hours of darkness. Melatonin regulates the circannual rhythms in reproductive processes. Melatonin reaching the suprachiasmatic nucleus of the hypothalamus inhibits the frequency and magnitude of the pulsatile secretion of hypothalamic and gonadotrophic hormones thereby inhibiting the release of pituitary hormones essential for initiation of reproductive activity. This pattern of neuro endocrine modulation which is influenced by the external light and via the pineal gland which causes the different effects through the secretion of melatonin is the key behind the initiation of reproductive activities in seasonal breeders [9]. Melatonin is also produced from the peripheral reproductive organs including granulose cells, cumulus oophorus and oocyte. It assists in maturation of oocyte, protects from free radical damage and also enhances the development of corpus lutuem and progesterone production [9].

\section{Neuro peptides which play a role in regulation of seasonal reproduction}

Kisspeptins: Evidences show that this neuro peptide regulates seasonal reproduction [10]. There is up regulation of kisspeptin expression in the ARC at the onset of the breeding season. Similarly, the number of kisspeptin fibers in close apposition to GnRH neurons [11]. The extent to which kispeptin cells provide input to $\mathrm{GnRH}$ neurons is greater during the breeding season than in non-breeding season [12]. Involvement of kispeptin cells in the positive feedback phenomena is consistent with the induction of preovulatory like $\mathrm{LH}$ surge in ewes following placement of estrogen implants in mediobasal hypothamus [13]. Work in seasonal rodents also provide indication that photoperiod change in kisspeptin levels is due to alterations in photoperiod driven by the changes in pattern of melatonin secretion [14]. In sheep melatonin acts with in premammilary nucleus of the basal hypothalamus to effect seasonal change in breeding [15]. Acyclicity in female sheep during non-breeding season is associated with reduced kispeptin function; treatment with the same can induce ovulation [16]. It is a potent $\mathrm{GnRH}$ secretogoge, which drives most aspects of reproduction in mammals [17].

GnIH (Gonadotrophin Inhibitory Hormone): This neuropeptide is involved in the inhibitory regulation of both $\mathrm{GnRH}$ secretion and gonadotropin release from the pituitary gland in mammals [18]. There is both a reduction in $\mathrm{GnIH}$ expression as well the number of $\mathrm{GnIH}$ fibers in close apposition to GnRH at the onset of the breeding season. Exogenous $\mathrm{GnIH}$ administration blocks both the pulsatile release of LH and the preovulatory LH surge during the breeding season. Neurons in the hypothalamus that produce kisspeptin and gonadotropin-inhibitory hormone $(\mathrm{GnIH})$ are important for the seasonal shift in reproductive activity, and the former are also mandatory for puberty onset. The integrated function of both these neuropeptide systems modulate the annual shift in photoperiod to a physiological change in fertility [3].

Dopaminergic A14/A15 neurons: The number of glutaminergic appositions onto dopaminergic A14/A15 neurons is greater during non-breeding season. Glutamate receptor antagonists increase pulsatile $\mathrm{LH}$ secretion in anestrous ewew when administered into the A14/A15 region [19]. Lesions of A14/A15 dopaminergiccell group led to disruption of seasonal breeding cycles and there is also a seasonal change in oestrogen negative feedback.

Activity of the thyroid gland: Functional thyroid glands are also essential for the transition from non-breeding to breeding season [4]. In sheep transfer to long day photoperiod induces increase in the expression of type 2 deiodinases in the mediobasal hypothalamus [20]. Male Saanen goats exposed to long day photoperiods showed an decreased expression of type 2 deiodinases and T3 content in hypothalamus [21]. Local metabolism of thyroid hormone by tanycyte cells within the mediobasal hypothalamus is the key seasonal gateway 
Page 3 of 4

for activation of the GnRH. Change in concentration of thyroid hormones appears central in seasonal breeding and they have direct effect on the plasticity of central nervous system [22].

\section{Regulation in seasonal and non-seasonal breeders}

Seasonal (long day) breeders: As the name says these animals specifically breed during long periods of day light or long photo periods. In the transition of season from the short periods of day light to long periods of day light, the photo receptors of the eye sensitize the same and there by the same information is passed to the pineal gland which then removes its inhibitory action on the hypothalamus. In these long day breeders the inhibitory effect of the pineal gland occurs during the short days of late fall and winter. This is the reason for which mares, stallions and other equids remain in anestrous during the short days. Once the season changes with increasing photoperiod into long days, the pineal gland becomes less active and thereby the secretion of melatonin is also reduced considerably. The inhibitory influence on the hypothalamus is removed. As a result of which the hypothalamic releasing factors and pituitary hormones are also secreted to initiate the reproductive process for the onset of breeding. The young ones are produced during spring and summer.

Seasonal (short day) breeders: Changing photoperiod from longer day light to shorter days with more periods of darkness iniatiates the reproductive activity in sheep and goat due to increase in melatonin secretion. The increased melatonin secretion reaching the hypothalamus, then stimulates the pulsatile secretion of $\mathrm{GnRH}$. Subsequently, FSH and LH secretion from the pituitary gland increases, which in turn results in the onset of ovarian activity and the commencement of the breeding season. They experience an annual period of reproductive quiescence in response to increased photoperiod during the late-winter into spring and renaissance during the late summer [10]. The nonbreeding (anestrous) season is characterized by a reduction in the pulsatile secretion of $\mathrm{GnRH}$, in part because of an increase in negative feedback activity of estrogen [4]. On the other way changing season from short days to long days forces them to experience an annual period of reproductive quiescence in response to increased photoperiod during the late-winter into spring and renaissance during the late summer [3]. The so called nonbreeding (anestrous) season is characterized by a reduction in the pulsatile secretion of $\mathrm{GnRH}$ in part because of an increase in negative feedback activity of estrogen [4].

Non seasonal breeders (polyestrous): In wild and domestic pig, as in other seasonal breeders, melatonin relays photoperiodic information about season to the pituitary-gonadal axis. Although photoperiod is considered the primary environmental cue to seasonal infertility, other environmental factors also seem to interact with season to affect the infertility. These include housing (group vs. individual), feeding level, light conditions, boar exposure, group size, ambient temperature and interactions between females. The significance of seasonal infertility has increased in recent years as group housing of dry sows has become more common [1].

Opportunistic breeders: They are typically capable of breeding at any time or becoming fertile within a short period of time. They are distinct from seasonal breeders that rely on changes in day length to induce estrus and to cue mating, and continuous breeders like humans that can mate throughout the year. An example is the golden spiny mouse where changes in dietary salt in its desert habitat due to rainfall appear to cue reproductive function [23]. Increased levels of salinity in drying vegetation cause females to experience a reproductive hiatus.
Since changes in season can coincide with favorable changes in environment, we cannot differentiate seasonal and opportunistic breeder. In equatorial climates, the change in seasons is not always perceptible and thus, changes in day length not remarkable. Thus, the tree kangaroo (Dendrolagus) previously categorized as a seasonal breeder is now suspected to be an opportunistic breeder. Other examples of mammals with such breeding pattern are tree kangaroo and musk shrew. Many opportunistic breeders are non-mammals. Those that are mammals tend to be small rodents [24].

General Factors having an influence on seasonal reproduction in any animal can be classified as intrinsic and extrinsic factors [25].

Intrinsic factors: They are related to genotype, and belong to the individual itself, extrinsic factors are related to the animal's environment. Life expectancy of the animal, as related to annual environmental variations is main intrinsic factor, where an animal having a life expectancy of one year or less, barely express seasonality, and develops into opportunistic breeder. Alternatively, if it has a life expectancy of several years, will have more chances of giving birth to viable offspring when restricting births to the most favorable seasons of the year. Similarly, the bigger the body size, the higher the chances of expressing seasonal reproduction, since a bigger animal has bigger energetic body stores, and can postpone easily its breeding activity to seasons more favorable for the newborn. Body size is, however, less important than both life expectancy and diet flexibility: an animal depending on a reduced spectrum of food will generally breed much more seasonally than an animal of similar traits but which is able to feed on a more flexible and varied diet.

Environmental (extrinsic) factors: Generally, the most important factor is food availability and its influence on energetic balance [26], as reproduction is energetically highly demanding. Breeding activities will suffer a strong selective pressure to occur in seasons of the year when most food is available, generally in spring and summer. Other factors which might be of importance are intra- and inter-species competition for resources, as well as strategies aiming at avoiding or limiting predation on offspring.

Latitude and Seasonality: High latitudes display great annual variations in photoperiod and ambient temperature. Animals adapted to such climates have short, well-defined breeding seasons, whereas tropical latitudes, where photoperiod and temperature vary little along the year, are inhabited by many more animals with long breeding seasons, and many tropical animals breed all year round [27].

Ambient temperature can also be a factor, since warmer temperatures could trigger reproductive activity. Conversely, too high temperatures could limit reproductive activity [28-32].

\section{Conclusion}

Seasonal breeding is under the control of central circadian regulatory system located in the SCN. It controls through neuroendocrine mechanism involving the hypothalamus, pituitary and pineal gland. The cyclic melatonin production is the primary cue controlling the onset of breeding. However, there are many other neuropeptides systems involved in the regulation of seasonal breeding. It is the up regulation of stimulators and down regulation of inhibitors along with the change in photoperiod that causes for the onset of breeding season. Not less importantly there are other environmental cues that influence seasonal breeding like the fluctuations in environmental temperature, climate variation, availability and quality 
Page 4 of 4

of feed etc. Studies in various species of animals is being carried out to exploit the different factors that affect the onset of breeding season, so that the reproductive performance of the animals can be improved. In summary, it is the integrated function of all the neuropeptide systems along with the circadian and melatonin rhythms regulated by the hypothalamus, that modulate the annual shift in photoperiod to a physiological change in fertility.

\section{References}

1. Nakao N, Ono H, Yoshimura T (2008) Thyroid hormones and seasonal reproductive neuroendocrine interactions. Reproduction 136: 1-8.

2. Foster DL (1988) Puberty in the female sheep. Knobil E, Neill JD (eds.). Physiology of Reproduction, Raven Press, New York, USA.

3. Smith JT (2012) The role of kisspeptin and gonadotropin inhibitory hormone in the seasonal regulation of reproduction in sheep. Domest Anim Endocrinol 43: 75-84.

4. Smith JT, Clarke IJ (2010) Seasonal breeding as a neuroendocrine model for puberty in sheep. Molecular and Cellular Endocrinology 324: 102-109.

5. Barrell GK, Moenter SM, Caraty A, Karsh FJ (1992) Seasonal changes of gonadotrophin releasing hormone secretion in the ewe. Biology of reproduction 46: 1130-1135.

6. Foster DL, Ryan KD (1979) Endocrine mechanisms governing transition into adult hood: a marked decrease in inhibitory feedback action of estradiol on tonic secretion of $\mathrm{LH}$ in the lamb during puberty. Endocrinology 105: 896-904.

7. Karsch FJ, Dahl GE, Evans NP, Manning JM, Mayfield KP, et al. (1993) Seasonal changes in gonadotropin-releasing hormone secretion in the ewe: alteration in response to the negative feedback action of estradiol. Biol Reprod 49: 1377-1383.

8. Wood S, Loudon A (2014) Clocks for all seasons: unwinding the roles and mechanisms of circadian and interval timers in the hypothalamus and pituitary. Journal of Endocrinology 222: R39-R59.

9. Reiter RJ, Tamura H, Tan DX, Xu XY (2014) Melatonin and the circadian system: contributions to successful female reproduction. Fertility and Sterility 102: 321-328.

10. Clarke IJ, Smith JT, Caraty A, Goodman RL, Lehman MN (2009) Kisspeptin and seasonality in sheep. Peptides 30: 154-163.

11. Wagner GC, Johnston JD, Clarke IJ, Lincoln GA, Hazlerigg DG (2008) Redefining the limits of day length responsiveness in a seasonal mammal. Endocrinology 149: 32-39.

12. Smith JT, Coolen LM, Kriegsfeld LJ, Sari IP, Jaafarzadehshirazi MR, et al. (2008) Variation in kisspeptin and RFamide-related peptide (RFRP) expression and terminal connections to gonadotropin-releasing hormone neurons in the brain: a novel medium for seasonal breeding in the sheep. Endocrinology 149: 5770-5782.

13. Caraty A, Fabre-Nys C, Delaleu B, Locatelli A, Bruneau G, et al. (1998) Evidence that the mediobasal hypothalamus is the primary site of action of estradiol in inducing the preovulatory gonadotropin releasing hormone surge in the ewe. Endocrinology 139: 1752-1760.

14. Simonneaux V, Ansel L, Revel FG, Klosen P, Pévet P, et al. (2009) Kisspeptin and the seasonal control of reproduction in hamsters. Peptides 30: 146-153.
15. Malpaux B, Tricoire H, Mailliet F, Daveau A, Migaud M, et al. (2002) Chemineau. Melatonin and seasonal reproduction: understanding the neuroendocrine mechanisms using the sheep as a model. Skinner DC, Evans NP, Doberska C (eds.). Large Mammals as Neuroendocrine Models, Supplement 59: 167-179.

16. Caraty A, Smith JT, Lomet D, Ben Said S, Morrissey A, et al. (2007) Kisspeptin synchronizes preovulatory surges in cyclical ewes and causes ovulation in seasonally acyclic ewes. Endocrinology 148: 5258-5267.

17. Oakley AE, Clifton DK, Steiner RA (2009) Kisspeptin signaling in the brain. Endocr Rev 30: 713-743.

18. Ubuka T, Lai H, Kitani M, Suzuuchi A, Pham V, et al. (2009) Gonadotropin-inhibitory hormone identification, cDNA cloning, and distribution in rhesus macaque brain. J Comp Neurol 517: 841-855.

19. Singh SR, Hileman SM, Connors JM, McManus CJ, Coolen LM, et al. (2009) Estradiol negative feedback regulation by glutamatergic afferents to A15 dopaminergic neurons: variation with season. Endocrinology 150: 4663-4671.

20. Hanon EA, Lincoln GA, Fustin JM, Dardente H, Masson-Pévet M, et al. (2008) Ancestral TSH mechanism signals summer in a photoperiodic mammal. Curr Biol 18: 1147-1152.

21. Yasuo S, Nakao N, Ohkura S, Iigo M, Hagiwara S, et al. (2006) Long-day suppressed expression of type 2 deiodinase gene in the mediobasal hypothalamus of the Saanen goat, a short-day breeder: implication for seasonal window of thyroid hormone action on reproductive neuroendocrine axis. Endocrinology 147: 432-440.

22. Bernal J (2002) Action of thyroid hormone in brain. J Endocrinol Invest 25: $268-288$.

23. Shanas U, Haim A (2004) Diet salinity and vasopressin as reproduction modulators in the desert-dwelling golden spiny mouse (Acomys russatus). Physiol Behav 81: 645-650.

24. Malpoux B (1999) The Neuroendocrine Control of Seasonal Rhythms. In: Conn PM, Freeman ME (eds.). Neuroendocrinology in physiology and medicine. Humana Press, p: 437.

25. Bronson FH (1989) Mammalian reproductive biology. The University of Chicago Press. pp: 51-52.

26. Bronson FH (2009) Climate change and seasonal reproduction in mammals. Philos Trans R Soc Lond B Biol Sci 364: 3331-3340.

27. Bronson FH (1988) Mammalian reproductive strategies: genes, photoperiod and latitude. Reproduction Nutrition Development 28: 335-347.

28. Haim A, Shanas U, Zubidad Ael S, Scantelbury M (2005) Seasonality and seasons out of time--the thermoregulatory effects of light interference. Chronobiol Int 22: 59-66.

29. Adams VL, Goodman RL, Salm AK, Coolen LM, Karsch FJ, et al. (2006) Morphological plasticity in the neural circuitry responsible for seasonal breeding in the ewe. Endocrinology 147: 4843-4851.

30. Foster DL, Karsch FJ (1975) Development of the mechanism regulating the preovulatory surge of luteinizing hormone in sheep. Endocrinology 97: 1205-1209.

31. Pineda M, Dooley MP (2003) McDonald's Veterinary Endocrinology and Reproduction. 5th edn. VEAR.

32. Ungerfeld U, Bielli A (2000) Seasonal and Social Factors Affecting Reproduction. Animal Reproduction in Livestock. Animal reproduction in Livestock. Encyclopedia of Life Support Systems. 